\title{
Emerging technologies for learning in occupational safety and health: the experience of the videogame "Becoming safe"
}

\section{Emma Pietrafesa, Rosina Bentivenga, Sara Stabile}

Department of Occupational and Environmental Medicine, Epidemiology and Hygiene, INAIL, Italy.

\begin{abstract}
In the paths for transversal skills and orientation (PCTO), italian students are considered like workers and therefore they must receive adequate information and training on occupational safety and health (OSH). These methods allow the students not to be excluded from the preventive measures of the health and safety at work by directing them towards self-protection. Today, this process can be supported through the use of digital tools such as videogames. The study describes a participative research and co-design work in 7 Italian high schools of agricultural, construction and manufacturing sectors, in order to co-create an educational tool (videogame) to promote OSH during the PCTO. The format could be a support for training and usable both in the classroom and in internship, according to the indications for the serious game's design. The study applied qualitative and quantitative methods: survey (277 students), word cafés/focus groups (50 students), 10 semi-structured interviews and 3 WhatsApp groups (12 students) to facilitate the participation and the engagement of teachers, students and OSH experts. Learning by playing has always been an activity, technologies today make it easy and funny, while gaming can offer cognitive and operational elements suitable for recognizing and therefore preventing the occupational risks.
\end{abstract}

Keywords: Gamification; occupational safety and health; school; learning; videogame. 


\section{Introduction}

The EU Strategic Framework on Health and Safety at Work 2014-2020, (EC, 2014) states that "OSH awareness begins at school" and calls on the Member States to take greater account of OSH issues in school curricula, particularly in vocational training courses. The COVID19 emergency highlighted the crucial importance of health, including the field of occupational safety and health (OSH). In the context of a definition of the education systems, the European Union introduced digital competence among the 8 key elements for lifelong learning of European citizens, demonstrating the centrality of digital in lifelong learning (EC, 2018). The European Commission, faces to the challenge of digital innovation, recently decided to promote a single Digital Education Action Plan which has 3 priorities: 1) Make better use of digital technologies for teaching and learning; 2) Develop digital skills and skills relevant to digital transformation; 3) Strengthen education through better data analysis and forward-looking analysis (EC, 2018). The Italian paths for transversal skills and orientation (PCTO) are promoted by schools for transversal activities to enhance the formative value of ongoing orientation. The focus is on the educational value of the concrete work experience as lever for a wider and more flexible knowledge overcoming the distance between education and professional training (Gentili, 2016). It is an opportunity to promote PCTO paths, which encourage young people to have work activation processes and conscious social identity since the alternation between work and study uses everything' student to acquire skills in the work context which will then be redefined and systematized at school (Stabile, 2019). In this context, a study conducted in France in 2018 found that for young workers, who received OSH teaching at school, the occupational accident rate is $50 \%$ lower than for young workers who did not (INRS, 2018).

\section{The role of gamification in training from serious game to digital tools}

Studies on gamification focused mainly on human machine interaction, analyzing its effectiveness and the factors that influence learning, such as motivation and attention (Vezzoli, 2018). The gamification is connoted as an approach that refers to the use of typical elements of the game such as mechanics, structure, aesthetics, thought, metaphors in contexts not of game (Deterding, 2011; Faiella, 2015). The concept of gamification is often used in relation to different situations concerning the widespread use of videogames to arouse and maintain the interest of students in learning contexts, with the aim of involving them and encouraging them to achieve increasingly ambitious goals, following the rules and having fun at the same time. It is therefore highlighted how gamification can be a methodology directly aimed at increasing engagement and promoting greater motivation during the performance of a task. The purpose of each game is to influence the psychological and social behavior of the player. Some elements present in the games (badges, points, levels, avatars, etc.) push players to increase the time devoted to the game itself and to be predisposed to 
continue it (Díaz Cruzado, 2013). Gamification also allows to satisfy the needs identified in the field of self-determination theory (Deci, 1985), which concern: the relationship, as a universal need for contact with others; competence, as a requirement to perceive oneself as effective and able in a given environment; autonomy, as a need to control one's own life. In line with the theory it could provide, it would be driven by an improvement of itself, rather than by the search for an external gratification (rewards) (Deterding, 2011). Other features of gamification refer to the possibility of being able to adapt it to the context, that is to be customized, to meet the educational needs of students and the needs of teachers (Gooch, 2016) and to identify models of response to these needs and also to implement educational intervention, monitoring and evaluation (de Santana, 2016). This methodology helps students to take initiatives and become more proactive too (Bowker, 2016), encouraging them to face new and challenging situations without fear of failure (Chung-Ho, 2013). Games, thanks to their cognitive and affective mechanisms, make it possible to achieve collateral learning and learning through learning by doing experience, on which the development of skills and competences is based (Benassi, 2013). Serious games, games with an explicit and welldefined educational purpose, not primarily designed for fun, but without excluding it (Abt, 1987), are innovative tools to promote also opportunities for growth and psychological wellbeing and could be introduced as positive technologies that influence both individual experiences and interpersonal relationships fuelling positive emotions, promoting engagement and improving social integration and connection (Argenton, 2014). Serious games and games are generally closely related to positive emotional experiences and a wide variety of pleasant responses that make the game the direct emotional opposite of depression (McGonigal, 2011). They can arouse pleasure for knowledge, stimulating curiosity and the desire for novelty in a protected environment where people experience the complexity of themselves and develop mastery and control, strengthening independence, self-confidence and self-esteem (Oatley, 2006). They promote the pleasure of victory and, by supporting virtual interactions with real people, feed social pleasure, encouraging collaborative and competitive dynamics through communication and sharing opportunities, even outside the context of the game (Reeves, 2009). To interact with young people today, it is important to use methods that are appropriate to this target group and that stimulate their interest. In this sense, digital gives a lot of opportunities offerring the possibility to experiment new tools and languages.

\subsection{Technology for learning: the value of videogames}

In Italy, in 201816.3 millions of people (aged 6- 64) played videogames: the $37 \%$ of the Italian population within this age range (54\% men and 46\% women) (Aesvi, 2019). According to Italian Interactive Digital Entertainment Association (IIDEA) the 2020 was the year of records for videogames: the turnover developed by videogames reached 2 billion and 179 million euros, with a growth of $21.9 \%$ compared to the previous year. The number of 
gamers remained unchanged, with 16.7 million people enjoying themselves with a joypad in hand, i.e. $38 \%$ of the Italian population aged between 6 and 64 . Indeed, the vast majority of psychological research on the effects of "gaming" has been focused on its negative impact: the potential harm related to aggression, addiction, and depression (Granic, 2013). Some studies consider the benefits that videogames could have in several domains: cognitive (e.g., attention), motivational (e.g., resilience in the face of failure), emotional (e.g., mood management), and social (e.g., prosocial behavior). Moreover, an increasing number of serious games applied in education are emerging because the educational elements can be integrated into the gameplay, which will be subconsciously acquired by the players during the gaming process. (Zhonggen, 2019). Easiness of use, elements of surprise in the storyscript, open-ended situations have been found as influential factors for the effectiveness in learning outcomes, especially among young players.

\section{Materials and methods}

Starting from international and national literature's review, a participative research and codesign work in 7 Italian high schools - agricultural, construction and manufacturing sectors was realized to co-create an educational tool (videogame) in order to promote OSH during the PCTO program. The study applied qualitative and quantitative methods. The study actively involved students in the design of the gameplay mechanics as well as in making the main decisions regarding its educational contents. The participative co-creation followed these steps: a qualitative inquiry in 4 Italian high schools to engage 12 teachers and 50 students in individual interviews and focus group discussions about their representations of risks in general and in the workplace, but also about their learning and teaching experience; these meetings created a smaller voluntary group of 12 students as "peer ambassadors", who had the task to make other interviews to their friends and other acquaintances and to interact with researchers (face-to-face and via instant messaging platforms) about the videogame design; a quantitative survey by questionnaire, in collaboration with the OSH experts, addressed to 277 students (63\% boys and $37 \%$ girls) of the last three years of 7 high schools, in order to deepen and verify the knowledge of their representations of risk and learning activities on occupational safety and health, and evaluate their gained skills in risk prevention; the development of the videogame "Becoming safe", in collaboration with the developers of a software house, who were invited to participate in the beta test as well; the organization of a first competition encouraging team participation, with 75 students of 2 high schools and a user survey about the satisfaction and commentaries on the videogame, through a questionnaire addressed to those 75 first players and by direct observation of their team gameplay; the final version of the videogame, adjusted following the observational and quantitative findings, with a game competition and final award among 39 students of 2 schools, one of which participated since the beginning of the project. 


\subsection{The Becoming safe project}

The research project was in collaboration between the University of Bologna and the National Institute for Insurance against Accidents at Work (Inail) ${ }^{1}$. A methodological path, aimed at co-creating a serious game, engaging all the different actors of OSH education - students, teachers, professional experts - was designed. No significant differences in academic achievements were found between digital learning and serious game use, but it is meaningful that significantly more positive attitudes toward serious game assisted learning were revealed compared with traditional paper-based learning, since they encouraged participation (Zhonggen, 2019). The structure of the videogame encourages entertainment and interaction to actively engage the players' agentive behaviors. The game is suitable both for individual and team play and therefore can be played cooperatively or competitively and it can be played on different devices (PCs, tablets, smartphones) ${ }^{2}$. It was designed as a learning tool and a support to mandatory training, to be used in and out the classroom, developing a good practice for $\mathrm{OSH}$ culture in accordance with technical and legal issues. Becoming safe is a management simulation game set in a 3D environment with a third-person overhead view, a choice that allows the player to navigate the game easily and move rapidly through the different scenarios. The goal is to win a race against time to prevent accidents, protect workers and build a safe workplace. Each student can play the role of a junior OSH manager, initially guided by a senior manager who explains the basic rules and regulations that have to be followed to guarantee the workers' safety (Pietrafesa, 2020).

\section{Results}

About 300 students from 7 technical institutes (42.6\% construction, 28.9\% manufacturing, $28.5 \%$ agricultural) and 12 teachers participated in the research. 10 teachers of the total sample took part in the semi-structured interview and 50 students who participated in 4 world café/focus groups, 3 Whatsapp groups were created for the involvement of 12 students. Finally, 277 students (63\% boys and $37 \%$ girls) from the last three years of the Institutes involved (III year 22.7\%, IV year 44.1\%, V year 33.2\%) answered to an anonymous ad hoc questionnaire: $92.5 \%$ of students report that they have already participated in PCTO, but only $27.1 \%$ (19.6\% boys and $31.4 \%$ girls) received OSH training. This training was certainly considered useful by $62.8 \%$ of young people, while compliance with the regulations guarantees to work safely for $69.7 \%$ of the sample (Table 1. .).

\footnotetext{
${ }^{1}$ Bando di Ricerca in Collaborazione (BRIC) 2016-2018 - ID 48 - financed by Inail in collaboration with Dipartimento di scienze politiche e sociali dell’Università “Alma Mater Studiorum” di Bologna - Scientific responsible Prof.ssa Pina Lalli - AUSL Modena, AUSL Viterbo e ASUR Marche A.V. 4 - Fermo.

${ }^{2}$ https://site.unibo.it/sicuri-si-diventa/it/gioca
} 

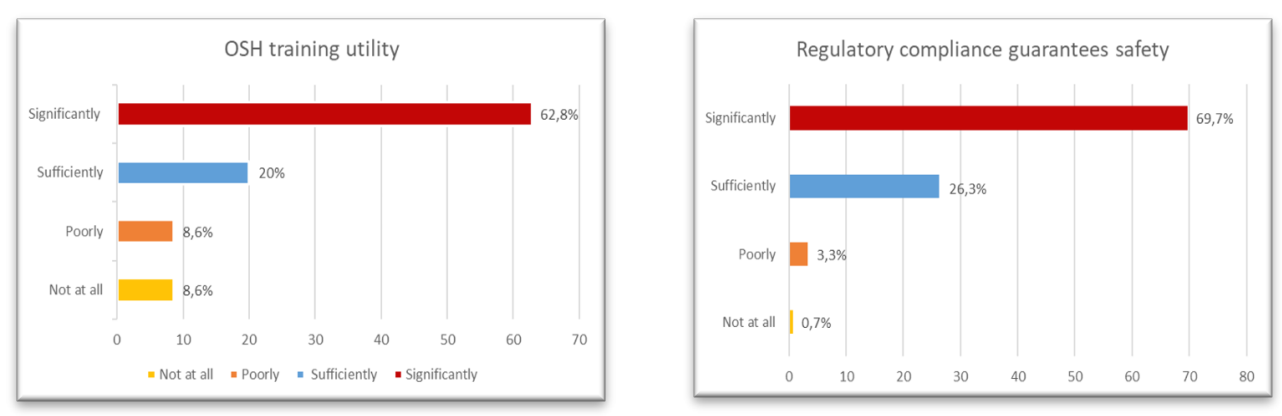

Figure 1. OSH Training utility in compliance with regulatory.

About $50 \%$ of the partipants considered the training with direct experience in the field to be the most effective training, followed by direct testimony of workers $(12.30 \%)$ and briefing in the classroom (12.30\%), while only 5.5\% indicated slides and explanations as the more effective method for OSH training (Table 2.).

\begin{tabular}{|c|c|c|c|c|c|c|}
\hline \multirow{5}{*}{$\begin{array}{r}0,6 \\
0,4 \\
0,2 \\
0\end{array}$} & \multicolumn{6}{|c|}{ Most effective OSH training methods } \\
\hline & & & & & & \\
\hline & & 12,3 & 12,3 & 11,9 & 8.5 & 55 \\
\hline & & $\square$ & $\square$ & 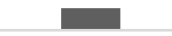 & $\square$ & 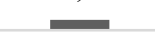 \\
\hline & $\begin{array}{l}\text { Direct } \\
\text { experience in } \\
\text { the field }\end{array}$ & $\begin{array}{c}\text { Direct } \\
\text { testimonies of } \\
\text { workers }\end{array}$ & $\begin{array}{l}\text { Briefing in the } \\
\text { classroom }\end{array}$ & $\begin{array}{l}\text { Videos and } \\
\text { images with } \\
\text { explanations }\end{array}$ & Simulations & $\begin{array}{l}\text { Slide and } \\
\text { explanation }\end{array}$ \\
\hline
\end{tabular}

Figure 2. The most effective OSH training methods.

According to the respondents, people at work were mainly at risk for lack of attention (61.3\%), for quickness (56.8\%), for relaxation (36.5\%) and for their own habits $(31.1 \%)$. As for the social representations of risk, the students associated it mainly to danger $(67.5 \%)$, injury (39\%), get hurt (30.3\%), unexpected (28.9\%) and distraction $(27.4 \%) .90 \%$ of the students liked the videogame as a whole, $55 \%$ thought it would be very useful to learn while having fun, $43 \%$ to know the rules of safety at work, $42 \%$ to become more aware of the risks at work and, finally, 26\% to remember the OSH rules at work, in particular those concerning the uses of the personal protective equipment (PPE), which played an important role in the game narrative. Almost all of the participants appreciated the game very much $(47 \%)$ and quite (43\%), while only $10 \%$ liked it fewer. 


\section{Conclusions}

Digital technologies can unlock new learning opportunities in the classroom by giving students access to a wider range of resources, by complementing the teacher in learning processes (computer-assisted learning) and by providing other advantages to students, such as access to motivational and informational resources associated with access to tertiary education programs. The evidence on the advantages of ICT resources in schools remains mixed. For real attitudinal change to take place and for new forms of action to be integrated, young people must first understand the importance of care and, as Morin assumed understanding that is a process that involves going beyond information, and it refers to identifying with others and empathy (Morin, 2002). Through the active behavior of the learning subjects, the ability to make conscious choices develops, an attitude develops, a "mental habit", a social and emotional mastery.

\section{References}

Abt, C. C. (1987). Serious games. University press of America.

Aesvi. (2019). I videogiochi in Italia nel 2018. Dati sul mercato e sui consumatori. Rapporto Associazione Editori Sviluppatori Videogiochi Italiani.

Argenton, L., Triberti, S., Serino, S., Muzio, M., \& Riva, G. (2014). Serious games as positive technologies for individual and group flourishing. In Technologies of inclusive well-being (pp. 221-244). Springer, Berlin, Heidelberg.

Benassi, A. (2013). Videogiochi e apprendimento collaterale. Italian Journal of Educational Technology, 21(3), 141-144.

Bowker, L. (2016). The Need for Speed! Experimenting with "Speed Training" in the Scientific/Technical Translation Classroom. Meta, 61, 22-36.

Chung-Ho, S. \& Ching-Hsue, C. (2013). A Mobile Game-based Insect Learning System for improving the learning achievements. Science Direct, 103, 42-50.

Commissione Europea, Proposta di "Regolamento del Parlamento Europeo e del Consiglio che istituisce il programma Europa digitale per il periodo 2021-2027", Com (2018), 434 definitivo, Bruxelles, 6 giugno 2018) https://eur-lex.europa.eu/legalcontent/EN/TXT/PDF/?uri=CELEX:52018PC0434\&from=IT

Commissione Europea, Salute e sicurezza sul lavoro nell'UE: quadro strategico 2014-2020 (Com 2014) https://ec.europa.eu/social/main.jsp?catId=151\&langId=it

Consiglio Europeo, Raccomandazione sulle competenze chiave, Consiglio (2018). https://eur-lex.europa.eu/legal-content/IT/TXT/PDF/?uri=CELEX:32018H0604(01)

Deci, E. L., \& Ryan, R. M. (1985). Motivation and self-determination in human behavior. NY: Plenum Publishing Co.

de Santana, S. J., Souza, H. A., Florentin, V. A., Paiva, R., Bittencourt, I. I., \& Isotani, S. (2016, April). A quantitative analysis of the most relevant gamification elements in an online learning environment. In Proceedings of the 25th international conference companion on world wide web (pp. 911-916). 
Deterding, S., Dixon, D., Khaled, R., \& Nacke, L. (2011, September). From game design elements to gamefulness: defining "gamification". In Proceedings of the 15th international academic MindTrek conference: Envisioning future media environments (pp. 9-15).

Díaz Cruzado, J., \& Troyano Rodríguez, Y. (2013). El potencial de la gamificación aplicado al ámbito educativo. III Jornadas de Innovación Docente. Innovación Educativa: respuesta en tiempos de incertidumbre.

Faiella, F., \& Ricciardi, M. (2015). Gamification and learning: a review of issues and research. Journal of e-Learning and Knowledge Society, 11(3).

Gentili, C. (2016). L'alternanza scuola-lavoro: paradigmi pedagogici e modelli didattici. Nuova secondaria, 10, 16-37.

Gooch, D., Vasalou, A., Benton, L., \& Khaled, R. (2016). Using Gamification to Motivate Students with Dyslexia. CHI 2016 San Jose, CA Proceedings, 10.

Granic, I., Lobel, A., Engels Ruther, C.M.E. (2013). The benefits of playing videogames. American Psychologist, 69 (1), 66-78.

Institut National de Recherche et de Sécurité, INRS (2018). Synthèse étude INRS Accidentologie des jeunes travailleurs. Recevoir un enseignement en santé et sécurité au travail ré-duit le risque d'accidents du travail chez les moins de 25 ans.

McGonigal, J. (2011). Reality Is Broken: Why Games Make Us Better and How They Can Change the World. Penguin Press. New York, NY.

Morin, E. (2002). Seven complex lessons in education for the future. UNESCO

Oatley, K., Keltner, D., \& Jenkins, J. M. (2006). Understanding emotions. Blackwell publishing.

Pietrafesa, E., Bentivenga, R., Lalli, P., Capelli, C., Farina, G., \& Stabile, S. (2020, June). Becoming Safe: A Serious Game for Occupational Safety and Health Training in a WBL Italian Experience. In International Conference in Methodologies and intelligent Systems for Techhnology Enhanced Learning (pp. 264-271). Springer, Cham.

Reeves, B., \& Read, J. L. (2009). Total engagement: How games and virtual worlds are changing the way people work and businesses compete. Harvard Business Press.

Stabile, S., Milana, C., Bentivenga, R., \& Pietrafesa, E. (2019). Alternanza Scuola Lavoro: sviluppo di nuove competenze e tutela della salute e sicurezza sul lavoro. FORMAZIONE \& INSEGNAMENTO. Rivista internazionale di Scienze dell'educazione e della formazione, 17(1), 259-272.

Vezzoli, Y., \& Tovazzi, A. (2018). Il Valore Pedagogico della gamification: una revisione sistematica. Formazione \& Insegnamento. Rivista internazionale di Scienze dell'educazione e della formazione, 16(1), 153-160.

Zhonggen, Y. (2019). A meta-analysis of use of serious games in education over a decade. International Journal of Computer Games Technology. 